\title{
FATAL MYOCARDIAL INFARCTION IN A YOUTH OF FIFTEEN YEARS
}

\author{
BY \\ J. SYME, AND W. S. A. ALLAN \\ From the Royal Infirmary, Edinburgh
}

Until comparatively recent times, coronary atheroma was widely regarded as a result of the aging process. Increasing interest in the ætiological factors of this disease has therefore tended to direct attention to its occurrence in younger patients, in whom, one might assume, factors other than age are operative. It may be of interest to report the occurrence of fatal myocardial infarction in a youth of fifteen years, who had also an anomaly of the coronary circulation.

Case Report. A youth, aged fifteen years and eight months, was admitted to the Royal Infirmary, Edinburgh. Shortly before, while running across a playing-field, he had complained of sudden, severe pain in his left upper arm, had vomited, and had rapidly become unconscious. For two weeks he had experienced intermittent pain in the left upper arm both on exertion and at rest, accompanied by nausea and general malaise. Not long before that he had undergone a physical examination for entry to a Boys' Service and had been passed fit. Before the present illness he was capable of strenuous exercise.

On admission the patient had regained consciousness. He complained of sharp pain in the left upper arm and to a lesser degree across the præcordium. He was of asthenic build but well nourished. His skin was cold and pale and his respirations shallow but regular. Radial pulses were equal and of poor volume, the rate being 40 a minute, the rhythm regular. Blood pressure was 98/70 mm. $\mathrm{Hg}$. Heart sounds were faint and no murmurs were audible. There were no stigmata of Marfan's syndrome, and no other abnormality was found on physical examination. A cardiogram showed elevation of the S-T segments in leads II, III, and aVF, the S-T segment being depressed in the anterior chest leads, changes indicative of acute posterior myocardial infarction. Shortly after this, the patient, who was showing slight clinical improvement, suddenly died.

Necropsy Report. The abnormal findings were confined to the coronary arteries. The heart weighed $310 \mathrm{~g}$. and was of normal shape and size. There were no congenital abnormalities involving the chambers or valves. Multiple sections through the ventricles revealed two tiny foci of fibrosis in the lateral wall of the left ventricle. There was no endocardial fibrosis or sign of infarction on naked-eye examination.

Coronary Arteries (Fig. 1 and 2). The two chief findings were (i) right coronary artery thrombosis superimposed on a thick plaque of atheroma close to the origin of the vessel; and (ii) an anomalous circumflex artery arising from the anterior sinus of the aorta (the ostium on the right in Fig. 2) and running laterally in the atrioventricular groove, before taking its usual course over the lateral aspect of the left ventricle.

Fig. 2 shows three ostia in the anterior sinus. That on the left represents an insignificant accessory coronary artery, and that in the centre the right coronary artery which was predominant and of normal distribution: this artery was narrowed by a thick fatty atheromatous plaque for the first $11.5 \mathrm{~cm}$. of its course, but beyond this its wall was normal. Reference has already been made to the third ostium. The left coronary artery apart from the absence of its circumflex branch and its relatively small size was normal. The anomalous circumflex vessel was also free from atheroma.

Microscopic Examination. Several microscopic foci of healing infarction were present in the muscle of the left ventricle. In these areas groups of muscle cells have been replaced by loose connective tissue, capillaries and microphages. All foci were at the same stage of healing and were 

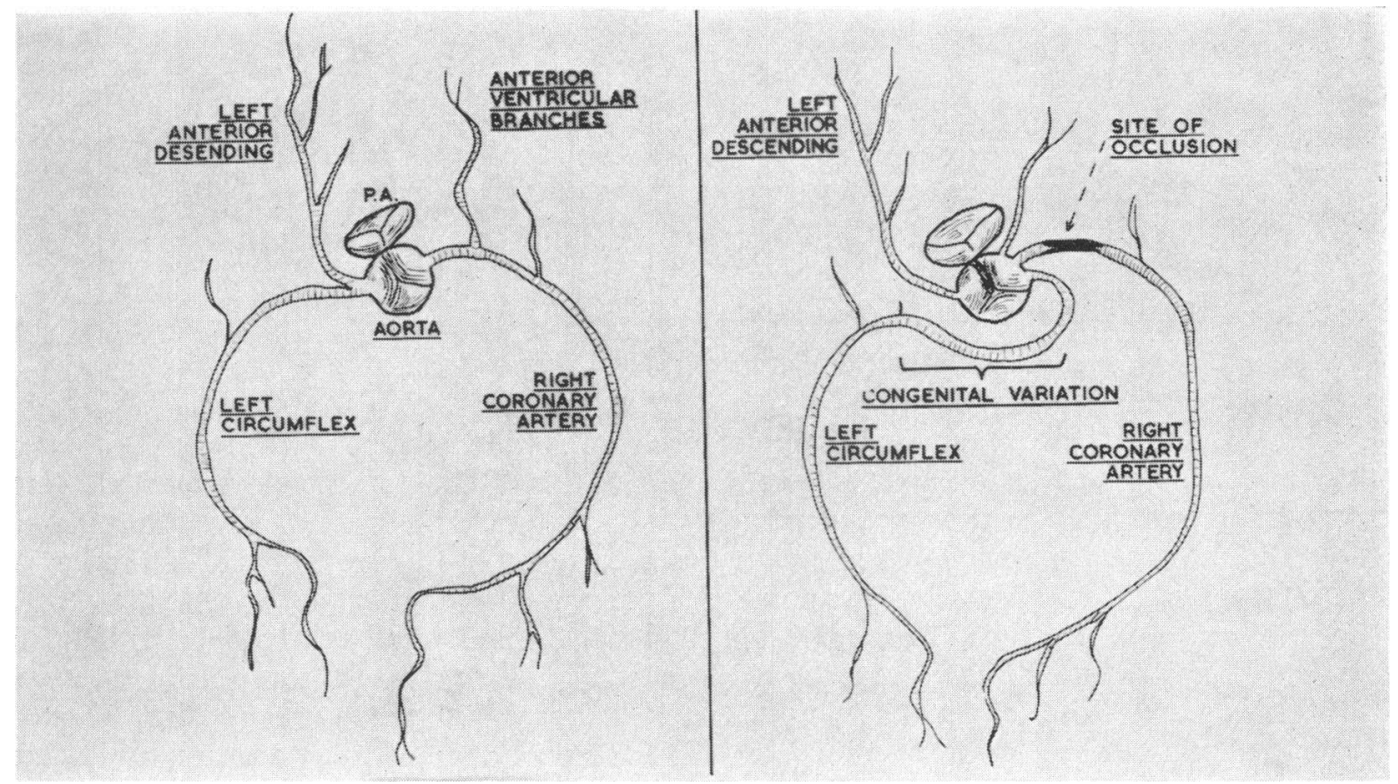

FIG. 1.-Diagram of coronary arterial origin and distribution in normal and in this case.

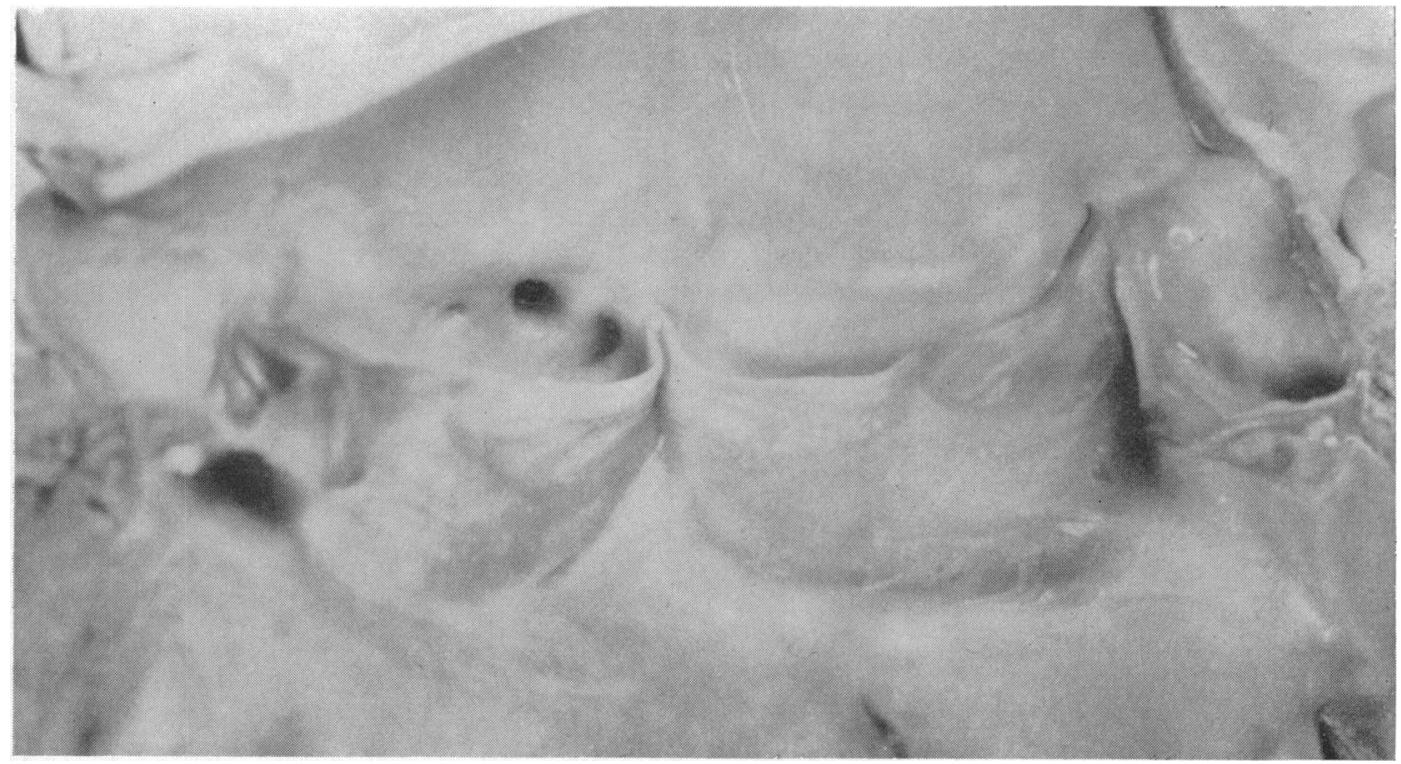

Fig. 2.-Anterior aortic sinus, showing three ostia.

estimated to be 7-14 days old. Elsewhere, the myocardium of the left ventricle showed in the area indicated by the electrocardiographic changes more diffuse evidence of very recent infarction in the form of patchy eosinophilia and blurring of the outline of individual muscle fibres.

Section of the right coronary artery showed eccentric thickening of the wall by a typical atheromatous plaque. The lumen was much reduced in size and, at one level, was almost completely occluded by thrombus showing signs of early organization. 
Blocks from the left coronary, the circumflex, and the middle of the right coronary arteries were also examined. All showed early degenerative changes, consisting of mild subintimal thickening due to increase of collagen and metachromatic ground substance. Focal disruption of the internal elastic lamina was another indication of early arterial degeneration. No sub-intimal lipid deposits were present. The vessels in other organs were also examined but no abnormalities found.

\section{Comment}

Congenital anomalies of the coronary arteries of clinical significance are uncommon. The anomaly most frequently recorded and of the greatest clinical importance is a left coronary artery arising from the pulmonary artery. Low oxygen tension of the blood transmitted by this vessel may lead to degeneration and fibrosis of the left ventricular myocardium. Origin of the right coronary artery from the pulmonary artery is apparently of less clinical importance. The explanation of the latter fact may be the relatively lower oxygen requirements of the right ventricular myocardium and the lower pressure in that chamber. Origin of both coronary arteries from the pulmonary artery has seldom been described: two cases survived only ten days after birth. Origin of an accessory coronary artery from the pulmonary artery appears to be of no clinical significance.

Anomalies of number and of distribution are more common and are rarely of clinical importance. Anomalous origin and course of the left circumflex coronary artery, with absence of a circumflex branch of the left coronary artery was described in a series by Antopol and Kugel (1933). Four autopsies revealed such anomalies, and occlusion of the right coronary artery was found in one of them at the site described in the case under discussion. This anomaly was also recorded by White and Edwards (1948) who found it in 4 out of 600 men's hearts examined at autopsy. Such a congenital defect does not appear to result in impairment, quantitative or qualitative, of the blood supply to the myocardium. After running laterally in the atrio-ventricular groove the anomalous vessel generally follows the normal course and distribution of the left circumflex coronary artery.

That coronary atheroma can occur in early youth is indicated by the report of Enos et al. (1953). In their autopsies on 300 U.S. service men killed in action in Korea, coronary arteriosclerosis varying in severity from subintimal thickening to complete occlusion of one or more vessels was found in 77 per cent. The average age of their series was 22 years, the youngest being 18 years old. The authors comment on the frequency and severity of atheromatous lesions at the sites of bifurcation, particularly where the angle of bifurcation approaches a right angle. They attribute the frequency of lesions at such sites to the eddies set up. It is difficult, however, to see how such observations can be relevant to the case described, in which occlusion took place in the right coronary artery which was not affected by the congenital anomaly.

It is difficult to dismiss as coincidental the association of an uncommon congenital anomaly of the coronary arteries with coronary atherosclerosis, thrombosis, and infarction in so young a subject. The authors, however, can suggest no causal relationship.

\section{Summary}

A case is described of fatal myocardial infarction in a youth of fifteen years, in whom at autopsy coronary atherosclerosis, thrombosis, and infarction were demonstrated, and in addition, anomalous origin of the circumflex branch of the left coronary artery.

Acknowledgments are due to Dr. J. D. S. Cameron, Physician in charge, for permission to publish this case, and to Dr. M. F. Oliver for his encouragement, criticism, and advice.

\section{References}

Antopol, W., and Kugel, M. A. (1933). Amer. Heart J., 8, 802

Enos, W. F., Holmes, R. H. and Beyer, J. (1953). J. Amer. med. Ass., 147, 621.

, (1956). J. Amer. med. Ass., 158, 912.

White, N. K. and Edwards, J. E. (1948). Arch. Path., 45, 766. 